\title{
Intracranial Brain Abscess in a Child with Cyanotic Congenital Heart Disease
}

\author{
Maithili Prakash Joshi ${ }^{1}$, Amar Mohanrao Taksande², Revatdhama Meshram³
}

1, 2, 3 Department of Paediatrics, Datta Meghe Institute of Medical Sciences, Sawangi, Wardha, Maharashtra, India.

\section{INTRODUCTION}

Congenital Heart Disease (CHD) is a leading cause of mortality in children. ${ }^{1,2}$ Brain abscess and cerebrovascular accidents are common neurological emergencies in unoperated children with cyanotic CHD which lead to mortality and morbidity in them. Frequency of brain abscess is found to be more than cerebrovascular accidents in such patients. ${ }^{3}$ These patients develop repeated brain abscesses secondary to polycythaemia-induced cerebral infarcts. Further, poor host immunity and bypass of lung phagocytosis are contributory factors. It require urgent intervention, or else they may lead to a midline shift and brain stem death, if left untreated. Children having a cyanotic congenital heart disease are likely to develop brain abscesses ${ }^{4}$ and vascular stroke. Polycythaemia, right to left shunt and high viscosity cause hypoxia and microinfarction in brain. Herewith, we present a case of a 9-year-old girl, a known case of cyanotic congenital heart disease with left sided brain abscess.

\section{PRESENTATION OF CASE}

A 9-year-old female child was brought to our hospital with complaints of vomiting and fever since 2 days. Vomiting was sudden in onset, non-bilious, non-projectile and foul smelling. She had fever which was intermittent, not associated with chills or any diurnal variation and relieved on taking medications. She was a diagnosed case of DTransposition of Great Arteries (TGA) with Ventricular Septal Defect (VSD) with moderate Pulmonary Stenosis (PS). There was no history of seizures, loss of consciousness, headache, blurring of vision or altered sensorium. On admission, she was conscious and oriented to time, place and person with a Glasgow Coma Scale (GCS) of 14 / 15. Vitals: Temperature: 98.4 degree F, heart rate: 110 / min, respiratory rate: 20 / min, blood pressure-100 / $64 \mathrm{~mm}$ of $\mathrm{Hg}$. Her oxygen saturation on room air was $80 \%$. She had central cyanosis and grade-3 clubbing in all four limbs. She had suffused conjunctivae. Fundus examination did not suggest of any papilledema. On cardiovascular examination, a grade 2 systolic murmur. On neurological examination: there was no cranial nerve involvement; there was hypertonia in all four limbs, exaggerated deep tendon reflexes, and extensor plantars. Meningeal signs-Kernig's and Brudzinski's sign could not be elicited. Laboratory parameters: Complete blood count: Haemoglobin: $20 \mathrm{~g} \%$, haematocrit- $65.7 \%$ white blood cells-15,800 cells / mm³, with $80 \%$ granulocytes, $15 \%$ lymphocytes, platelet count: 26,000 / mm 3 renal function test: urea- $43 \mathrm{mg} / \mathrm{dL}$, creatinine- $0.7 \mathrm{mg} / \mathrm{dL}$, sodium-148 mmol / $\mathrm{L}$ and potassium-5 mmol / L. Coagulation profile: International Normalized Ratio (INR)-1.28, Prothrombin Time (PT)-16 seconds, Activated Partial Thromboplastin Time (APTT)51.1 seconds (control-30 seconds). A blood culture was sent under all sterile precautions which did not show any growth after $2^{\text {nd }}$ subculture.
Corresponding Author: Dr. Maithili Joshi,

Meghe Heights 4,

Datta Meghe Institute of Medical

Sciences, Savangi, Wardha,

Maharashtra-442001, India.

E-mail: maithij188@gmail.com

DOI: $10.14260 / j e m d s / 2020 / 826$

How to Cite This Article:

Joshi MP, Taksande AM, Meshram R. Intracranial brain abscess in a child with cyanotic congenital heart disease. J Evolution Med Dent Sci 2020;9(49):37673769, DOI: $10.14260 /$ jemds/2020/826

Submission 29-08-2020

Peer Review 22-10-2020,

Acceptance 29-10-2020,

Published 07-12-2020.

Copyright (C) 2020 Maithili Prakash Joshi et al. This is an open access article distributed under Creative Commons Attribution License [Attribution 4.0 International (CC BY 4.0)] 
Widal test was negative and urine routine and microscopy which was s / o 1 - 2 pus cells without albuminuria or glycosuria. Magnetic resonance imaging of brain with contrast suggestive of a large lesion measuring $4.7 \times 3.4 \times 2.4$ centimeters with perilesional oedema in left fronto-parietal region with a midline shift of 5 millimeters to the right side with a central necrotic area suggestive of brain abscess (Figure 1).

\section{DISCUSSION OF MANAGEMENT}

The child was started with intravenous fluids, injection ceftriaxone and injection ondansetron in antiemetic doses. Owing to her deranged coagulation profile, we administered vitamin K $2.5 \mathrm{mg}$ intravenously for 3 days and administered fresh frozen plasma. Around $25 \mathrm{~mL}$ of pus was aspirated during the Burr Hole craniotomy. Pus was sent for staininggram and Ziehl-Neelsen, histopathology; s / o growth of enterococci species sensitive to vancomycin. She was given antibiotics for 14 days. Post-surgery, a computed tomography scan was done which showed e / o ill-defined area of hypodensity in left parietal and right occipitoparietal region and a calvarial defect in bilateral parietal region. (Figure 2). After a month long post-operative period, she did not have any $\mathrm{s} / \mathrm{o}$ neurological deficit, so she was discharged and advised to follow up after a week.

\section{DISCUSSION}

Intracranial abscess in the paediatric population is a rare occurrence-4 in a million; it is a focal, intra-cerebral infection that starts off as a localized lesion and finally develops into a collection of pus surrounded by a well-vascularized capsule. ${ }^{5}$ It is a rare complication of cyanotic congenital heart disease. The peak incidence occurs when the child is between 4 years and 7 years of age, although it may occur in adults with cyanotic congenital heart disease. ${ }^{6}$ In cyanotic heart disease, hyper viscosity of blood resulting from compensatory polycythaemia and the sluggish flow in the microcirculation of the brain forms an infarct by intravascular thrombosis. Along with this, decreased oxygen tension or brain hypoxia might enhance the flow of shunted blood containing microorganisms followed by focal cerebritis. ${ }^{7}$ Clinically, children usually present with vomiting, fever, headache, seizures, focal neurological signs \&amp; eventually papilloedema \&amp; coma, but these manifestations may be subtle at the initial stage. In our patient, she did not have any neurological symptoms apart from vomiting, which is again a non-specific finding. However, neurological signs prompted us to rule out brain abscess and stroke. She did not have paresis or paraplegia. Neuroimaging forms the mainstay in diagnosis. ${ }^{8}$ Optimal therapy depends on the size of the abscess, if less than 2.5 centimetres in diameter, they may be treated with antibiotics with a follow up neuroimaging study to look for a reduction in the size. If greater than 2.5 centimetres, aspiration maybe preferred. ${ }^{8}$ Our patient responded well by administration of meropenem and vancomycin. Postoperative care should be prompt and development of raised intracranial pressure should be avoided. Uncontrolled rise of intracranial pressure may lead to brain herniation. Osmotic diuretics and hypertonic saline can be administered for the same depending on child's haemodynamic status and serum electrolytes. Our patient received 6 doses of mannitol post operatively and she did not develop any signs of raised intracranial pressure.
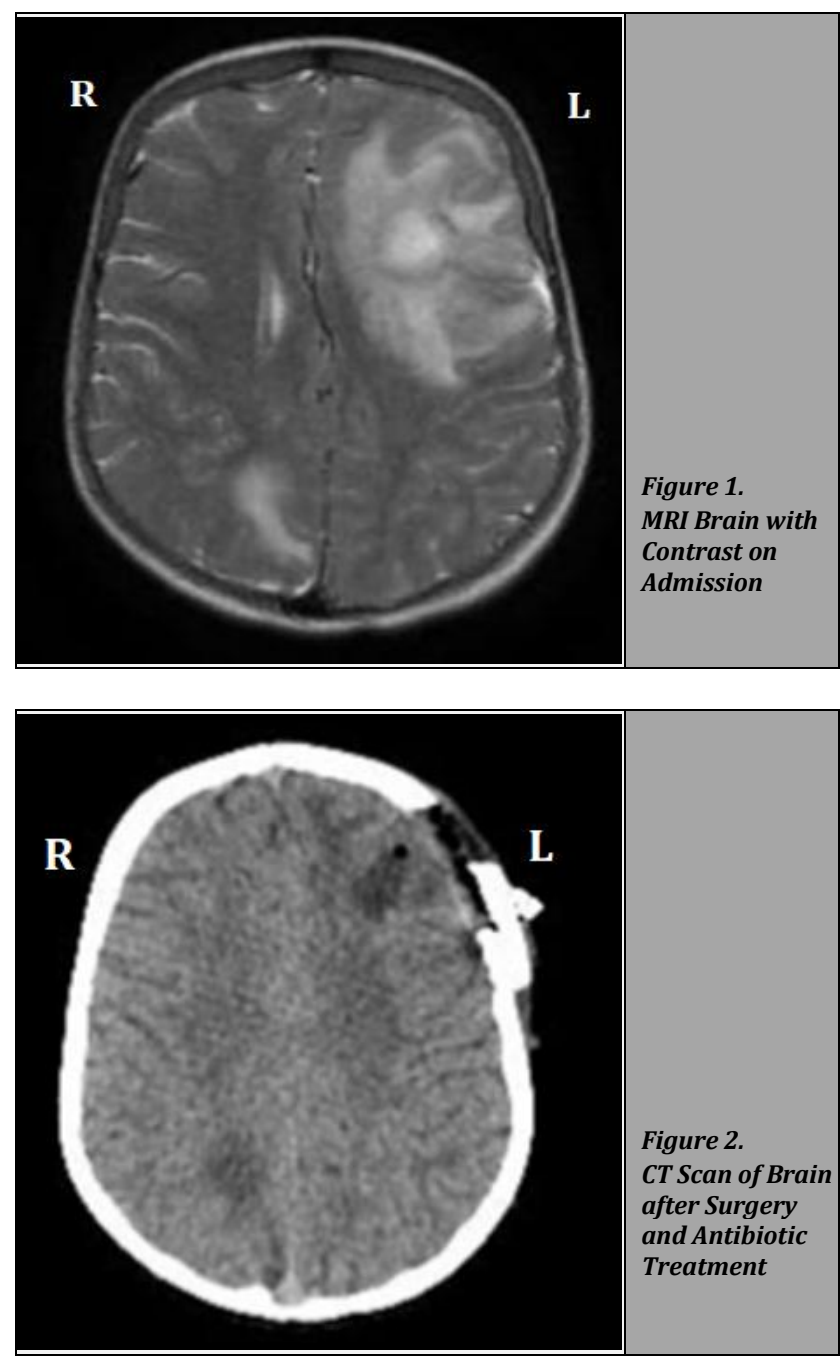

\section{CONCLUSIONS}

In a child with congenital cyanotic heart disease, focal neurologic abnormalities or signs of raised intracranial tension must be considered as indications of the probable presence of a brain abscess unless proven otherwise. Craniotomy plays an integral part in treatment of brain abscess with a favourable outcome, especially if the entire capsule is removed.

Financial or other competing interests: None.

Disclosure forms provided by the authors are available with the full text of this article at jemds.com.

\section{REFERENCES}

[1] Cassidy AR, White MT, DeMaso DR, et al. Executive function in children and adolescents with critical cyanotic congenital heart disease. J Int Neuropsychol Soc 2015;21(1):34-49. 
[2] Mehnaz A, Syed AU, Saleem AS, et al. Clinical features and outcome of cerebral abscess in congenital heart disease. J Ayub Med Coll Abbottabad 2005;18(2):21-4.

[3] Mameli C, Genoni T, Madia C, et al. Brain abscess in pediatric age: a review. Childs Nerv Syst 2019;35(7):1117-28.

[4] Ozsürekci Y, Kara A, Cengiz AB, et al. Brain abscess in childhood: a 28-year experience. Turk J Pediatr 2012;54(2):144-9.

[5] Ashraf M, Ahmed S, Ahmad S, et al. Burr hole aspiration of brain abscess in children with cyanotic heart disease. J Coll Physicians Surg Pak 2017;27(8):483-5.
[6] Piper C, Horstkotte B, Arendt G, et al. Brain abscess in children with cyanotic heart defects. Z Kardiol 1994;83(3):188-93.

[7] Raha A, Ganjoo P, Singh A, et al. Surgery for brain abscess in children with cyanotic heart disease: an anesthetic challenge. J Pediatr Neurosci 2012;7(1):23-6.

[8] Janowski AB, Hunstad DA. Brain abscess. In: Kliegman RM, St. Geme J, eds. Nelson textbook of pediatrics. 21st edn. Philadelphia: Elsevier 2020:3235-6. 